\title{
Enhanced long-term and impaired short-term spatial memory in GluAl AMPA receptor subunit knockout mice: Evidence for a dual-process memory model
}

\author{
David J. Sanderson, ${ }^{1,4}$ Mark A. Good, ${ }^{2}$ Kathryn Skelton, ${ }^{1}$ Rolf Sprengel, ${ }^{3}$ \\ Peter H. Seeburg, ${ }^{3}$ J. Nicholas P. Rawlins, ${ }^{1}$ and David M. Bannerman ${ }^{1}$ \\ ${ }^{1}$ Department of Experimental Psychology, University of Oxford, Oxford OX1 3UD, United Kingdom; ${ }^{2}$ School of Psychology, Cardiff \\ University, Cardiff CF10 3AT, United Kingdom; ${ }^{3}$ Max-Planck Institute of Medical Research, Department of Molecular Neurobiology, \\ Heidelberg D-69120, Germany
}

\begin{abstract}
The GluAl AMPA receptor subunit is a key mediator of hippocampal synaptic plasticity and is especially important for a rapidly-induced, short-lasting form of potentiation. GluAl gene deletion impairs hippocampus-dependent, spatial working memory, but spares hippocampus-dependent spatial reference memory. These findings may reflect the necessity of GluAl-dependent synaptic plasticity for short-term memory of recently visited places, but not for the ability to form long-term associations between a particular spatial location and an outcome. This hypothesis is in concordance with the theory that short-term and long-term memory depend on dissociable psychological processes. In this study we tested $\mathrm{GluAl}^{-I-}$ mice on both short-term and long-term spatial memory using a simple novelty preference task. Mice were given a series of repeated exposures to a particular spatial location (the arm of a Y-maze) before their preference for a novel spatial location (the unvisited arm of the maze) over the familiar spatial location was assessed. GluAl ${ }^{-1-}$ mice were impaired if the interval between the trials was short $(1 \mathrm{~min})$, but showed enhanced spatial memory if the interval between the trials was long $(24 \mathrm{~h})$. This enhancement was caused by the interval between the exposure trials rather than the interval prior to the test, thus demonstrating enhanced learning and not simply enhanced performance or expression of memory. This seemingly paradoxical enhancement of hippocampus-dependent spatial learning may be caused by GluAl gene deletion reducing the detrimental effects of short-term memory on subsequent long-term learning. Thus, these results support a dual-process model of memory in which short-term and long-term memory are separate and sometimes competitive processes.
\end{abstract}

[Supplemental material is available online at www.learnmem.org.]

Hippocampal synaptic plasticity has long been regarded as a potential substrate for spatial learning (Morris et al. 1986; Martin et al. 2000). It is mediated, in part, by an increase in the synaptic surface expression of AMPA receptors. This process is induced by NMDA receptor activation, and involves the regulated insertion of GluA1 (GluR-A, GluR1; see Collingridge et al. 2009) subunitcontaining AMPA receptors (Zamanillo et al. 1999; Malinow and Malenka 2002). GluA1 is especially important for a rapidly induced, short-lasting form of potentiation (Hoffman et al. 2002; Romberg et al. 2009). Mice lacking GluA1 (GluA1 ${ }^{-1-}$ mice) show normal acquisition of spatial reference memory tasks in which they must discriminate between always rewarded and nonrewarded locations, but, in contrast, they fail to discriminate between spatial locations during spatial working memory tasks (Zamanillo et al. 1999; Reisel et al. 2002; Schmitt et al. 2003).

One possible account of these results is that GluA1 is critical for forming a short-term memory trace that underlies the sense of familiarity for recently visited places (Sanderson et al. 2008). This hippocampus-dependent short-term memory may result in habituation to familiar spatial locations, and thus will cause a reduction in the tendency to explore a familiar location. This use of the term

\footnotetext{
${ }^{4}$ Corresponding author.

E-mail david.sanderson@psy.ox.ac.uk; fax 44-1865-310447.

Article is online at http://www.learnmem.org/cgi/doi/10.1101/lm.1339109. Freely available online through the Learning \& Memory open access option.
}

"short-term memory" is thus, consistent with Wagner's notion of short-term memory priming that can affect both stimulus processing and responding (Wagner 1976, 1978, 1979, 1981; Whitlow and Wagner 1984). Whereas normal mice preferentially explore a novel location over a familiar location, GluA1 knockout mice fail to show hippocampus-dependent short-term memory for a familiar spatial environment and consequently show an equal preference for exploring a novel location and a recently visited location (Sanderson et al. 2007). In contrast, GluA1 knockout (KO) mice can form hippocampus-dependent long-term associative memories between spatial locations and outcomes (such as rewards) (Zamanillo et al. 1999; Reisel et al. 2002; Schmitt et al. 2003).

It has been suggested that short-term and long-term memory are the result of dissociable psychological processes, subserved by nonassociative and associative learning mechanisms, respectively (Wagner 1976, 1981) and by different neurobiological mechanisms (e.g., Groves and Thompson 1970; Barker et al. 2006). In view of the preserved ability of GluA1 $1^{-/-}$mice to form associations involving spatial stimuli on reference memory tasks, it is predicted that long-term memory will be preserved in these mice, (Zamanillo et al. 1999; Reisel et al. 2002; Schmitt et al. 2003), whereas short-term memory is impaired. It has been shown previously that the length of the interval between stimulus exposures can determine both short-term and long-term effects on habituation (Davis 1970). Here we tested the effect of GluA1 gene deletion on short-term and long-term spatial memory by 
manipulating (1) the length of the interval between a series of exposure training trials and (2) the interval prior to the test of spatial memory (a novelty preference test involving a simultaneous choice between a familiar, previously exposed, spatial location and a novel location) (see Fig. 1A). In Experiment $1 \mathrm{~A}$ the exposure training trials to the familiar spatial location and the novelty preference test were separated by either a $1 \mathrm{~min}$ or $24 \mathrm{~h}$ intertrial interval (ITI) (see Fig. 1B). When the short (1 min) ITI is used, memory should be maximally influenced by short-term processes. However, when the long ( $24 \mathrm{~h}$ ) ITI is used, short-term memory should have decayed, and thus performance should be reliant on long-term memory. The effects of hippocampal lesions were also tested on the same task to assess the hippocampal dependency of both short-term and long-term spatial memory (Experiment 1B). In Experiment 2 the effects of both the exposure training trial interval (training ITI) and the interval prior to the novelty preference test (testing ITI) were tested in a factorial design to determine the role of GluA1 in both the acquisition of memory (as reflected by the effect of training ITI) and the expression of
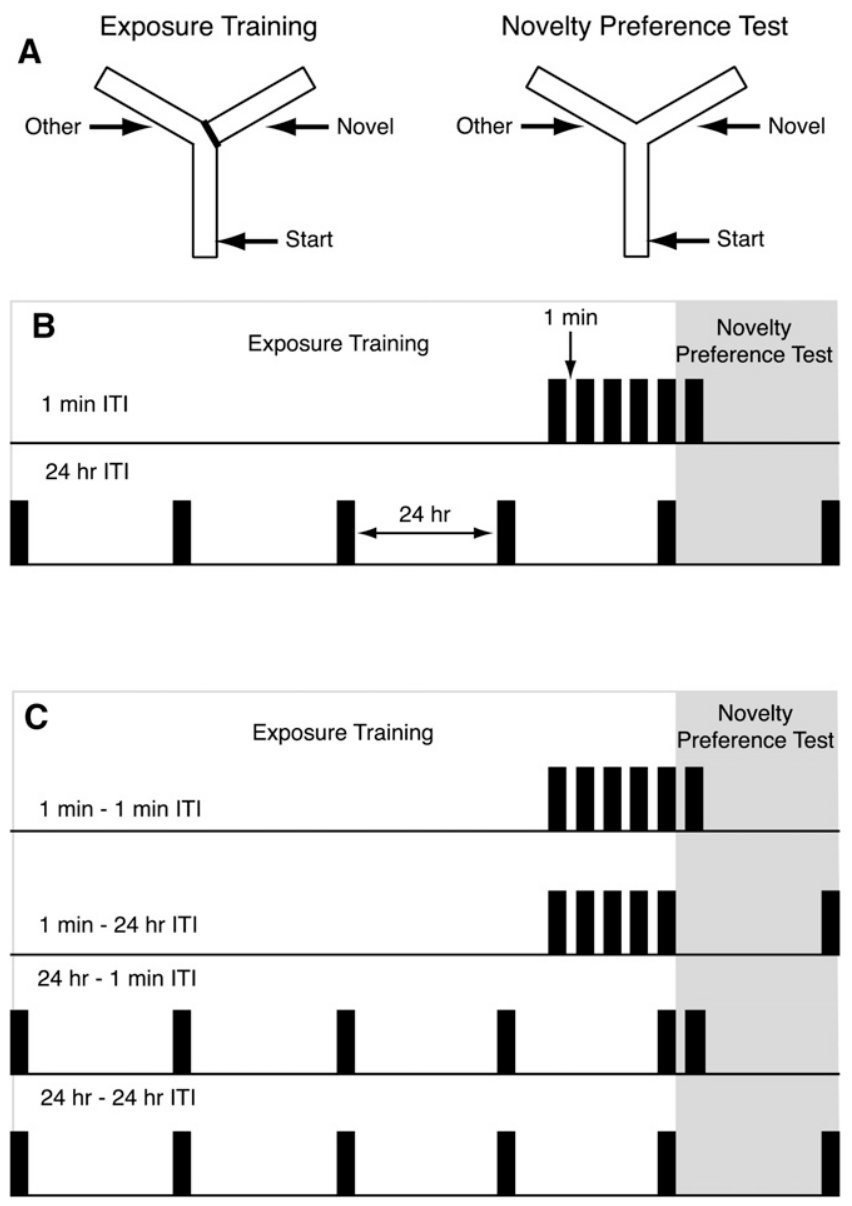

Figure 1. The design of Experiments 1 and 2. (A) During "Exposure training" mice were allowed to explore the Start arm and the Other arm for five 2-min trials. Access to the Novel arm was blocked. During the Novelty Preference Test mice were allowed to explore the two familiar arms (Start and Other) and the previously unvisited Novel arm for a period of $2 \mathrm{~min}$. (B) In Experiment 1 the interval between exposure trials and also the interval prior to the novelty preference test was either $1 \mathrm{~min}(1 \mathrm{~min}$ ITI) or $24 \mathrm{~h}$ ( $24 \mathrm{~h} \mathrm{ITI})$. (C) In Experiment 2, two groups of mice from each genotype received exposure training with a 1 min interval between trials and two further groups from each genotype received exposure training with a 24-h interval between trials. One group from each training condition received the novelty preference $1 \mathrm{~min}$ after the last training trial. The other group received the test $24 \mathrm{~h}$ after the last training trial. memory (as reflected by the effect of testing ITI; see Fig. 1C). We now demonstrate that whereas GluA1 ${ }^{-1-}$ mice displayed impaired short-term spatial memory, paradoxically their long-term spatial memory was enhanced relative to wild-types, providing support for Wagner's dual-process model of memory.

\section{Results}

\section{Experiment 1}

\section{Experiment $1 A$}

$\mathrm{GluA1}^{-/-}$mice were tested for both short-term and long-term memory of a spatial location. Mice received five 2-min exposure training trials to two arms of a Y-shaped maze (Start and Other arms). During the exposure training trials the number of arm entries was recorded. The habituation of activity (i.e., a decrease in the number of arm entries) over exposure training trials was differentially affected by genotype dependent on the ITI (see Supplemental material). Whereas wild-type (WT) mice showed greater habituation with a short (1 min) ITI than a long ( $24 \mathrm{~h})$ ITI, KO mice showed greater habituation with a short, rather than a long, ITI.

After exposure training, mice received a novelty preference test in which they were allowed to explore the previously unvisited, Novel arm and the previously visited, Start and Other arms (see Fig. 1B). The exposure trials and the novelty preference test were each separated by either $1 \mathrm{~min}$ ( $1 \mathrm{~min}$ ITI condition) or by 24 h (24 h ITI condition).

Wild-type mice showed a strong preference to explore the Novel arm in the 1 min ITI condition, whereas GluA1 $1^{-1-}$ mice did not show this preference. However, in the $24 \mathrm{~h}$ ITI condition, $\mathrm{GluA}^{-1-}$ mice showed a strong novelty preference, which was greater than the novelty preference in controls (Fig. 2A,B). The time in the Novel arm is shown as ratio of the total amount of time spent exploring the Other and Novel arms during each test (i.e., discrimination ratio: Novel/[Novel + Other]). Similarly, a discrimination ratio was calculated for the number of arm entries into the Novel and Other arms. Scores greater than 0.5 indicate a preference for the Novel arm. ANOVA revealed a significant genotype by ITI interaction for both measures (time in arms: $F_{(1,30)}=14.41, P<0.002$; number of arm entries: $F_{(1,30)}=15.03, P<$ 0.002 ). Simple main effects analysis confirmed that $\mathrm{GluA} 1^{-1-}$ mice were significantly impaired compared to controls when tested on the $1 \mathrm{~min}$ ITI condition (time in arms: $F_{(1,30)}=6.25$, $P=0.018$; number of arm entries: $\left.F_{(1,30)}=8.66, P=0.006\right)$, but were significantly superior to controls on the $24 \mathrm{~h}$ ITI condition (time in arms: $F_{(1,30)}=8.62, P=0.006$; number of arm entries measure: $\left.F_{(1,30)}=3.54, P=0.07\right)$. Furthermore, whereas wild-type mice showed a significantly greater novelty preference in the $1 \mathrm{~min}$ ITI condition than in the $24 \mathrm{~h}$ ITI condition (time in arms: $F_{(1,30)}=$ 19.06, $P<0.0005$; number of arm entries: $F_{(1,30)}=15.52, P<$ $0.0005)$, in knockout mice, although not statistically significant, there was a numerically greater preference in the $24 \mathrm{~h}$ ITI, than the 1 min ITI, condition (time in arms: $F_{(1,30)}=1.64, P=0.2$; number of arm entries: $\left.F_{(1,30)}=3.05, P=0.09\right)$. One sample of $t$-tests confirmed that at the 1 min ITI wild-type mice showed a novelty preference that was significantly above chance (i.e., discrimination ratio $>0.5$ ) (time in arms: $t_{(19)}=4.49, P<0.0005$; number of arm entries: $\left.t_{(19)}=6.36, P<0.0005\right)$, whereas knockout mice did not (time in arms: $t_{(13)}<1, P=0.65$; number of arms measure, $\left.t_{(13)}=1.96, P=0.07\right)$. However, with the $24 \mathrm{~h}$ ITI, knockout mice showed a preference that was significantly above chance (time in arms: $t_{(13)}=2.96, P=0.011$; number of arm entries: $t_{(13)}=3.82, P=$ 0.002 ), but wild-type mice did not (time in arms: $t_{(19)}=1.13, P=$ 0.3 ; number of arm entries: $\left.t_{(19)}=1.76, P=0.1\right)$. Male mice showed a stronger novelty preference than females (time in arms: $F_{(1,30)}=$ 

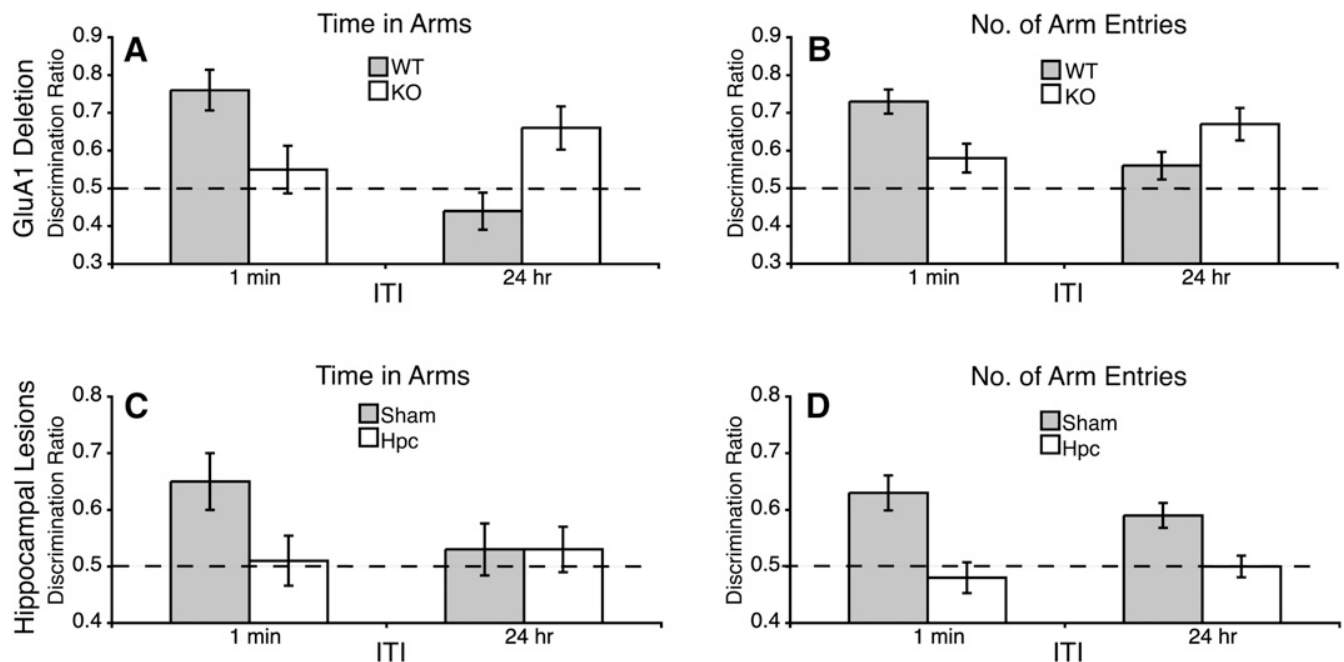

Figure 2. Experiment 1. The effect of GluA1 gene deletion and hippocampal lesions on short-term and long-term spatial memory. Preference for the Novel arm over the familiar Other arm is shown as a discrimination ratio (Novel/Novel + Other). The dashed line indicates chance performance $(0.5)$. $(A, C)$ Results from the time in arms measure. $(B, D)$ Results from the number of arm entries measure. $(A, B)$ GluA1 gene deletion impaired preference for the Novel arm when a $1 \mathrm{~min}$ ITI was used, but enhanced the preference for the Novel arm when a $24 \mathrm{~h}$ ITI was used (wild-type mice [WT]: female, $N=12$; male, $N=8$; knockout mice [KO]: female, $N=8$; male, $N=6)$. $(C, D)$ Hippocampal lesioned mice failed to show a preference for the Novel arm at either interval (sham lesioned mice [Sham]: $N=9$; hippocampal lesioned mice [Hpc]: $N=12$ ). Error bars, \pm SEM.

5.91, $P=0.02$; number of arm entries: $\left.F_{(1,30)}=4.12, P=0.05\right)$. However, this did not interact with genotype or ITI (all $P$-values $\geq 0.2$, both measures).

Importantly, during the 2 min novelty preference test both groups spent similar total amounts of time exploring the arms of the maze (WT: $86.17 \mathrm{sec} \pm 3.65 \mathrm{SEM}$; KO: $79.38 \mathrm{sec} \pm 4.32 \mathrm{SEM}$ ) (effect of group: $F_{(1,30)}=1.44, P=0.2$; group by ITI interaction: $F<$ 1). However, GluA1 ${ }^{-1-}$ mice made a significantly greater total number of arm entries than wild-type mice (WT: $4.98 \pm 0.71 \mathrm{SEM}$; KO: $7.55 \pm 0.84 \mathrm{SEM})\left(F_{(1,30)}=5.52, P=0.026\right)$. The effect of genotype did not significantly interact with ITI $(F<1)$. There was a significant interaction between sex and ITI $\left(F_{(1,30)}=17.15, P=\right.$ $0.0005)$ due to female mice making more arm entries than males in the $24 \mathrm{~h}$ ITI condition, but not in the $1 \mathrm{~min}$ ITI condition. There were no other main effects or interactions $(P>0.1)$. Additional analyses of the preference for the Novel arm using a difference score (Novel - Other) yielded a similar genotype by ITI interaction (see Supplemental material).

\section{Experiment $1 B$}

To assess the hippocampal dependency of both short-term and long-term spatial memory, hippocampal lesioned mice and sham controls were tested on the novelty preference task in a similar manner to Experiment 1A (see Fig. 1B). There was little variation between the lesions; a representative example is shown in Figure 3. Reconstructions of the smallest and largest lesions are provided in Supplemental Figure S7. Hippocampal lesioned mice had substantial damage to dorsal and ventral hippocampus, with little, if any, extra-hippocampal damage. The hippocampus was entirely removed, or remained only as damaged gliotic tissue, in most cases. Small amounts of intact tissue remained in a minority of mice. These were confined to a small amount of unilateral medial dentate gyrus sparing and some sparing of the posterior part of the ventral hippocampus. Most of the subiculum, particularly the preand parasubiculum, was spared in all cases.

During the exposure training trials the number of arm entries was recorded. The habituation of activity (i.e., a decrease in the number of arm entries) over exposure training trials was impaired by hippocampal lesions (see Supplemental material).
In the novelty preference test, hippocampal lesioned mice (Hpc) failed to show a novelty preference at either ITI (Fig. 2C,D). ANOVA of the number of arm entries discrimination ratio showed a significant effect of lesion $\left(F_{(1,19)}=19.99, P=0.0005\right)$. There was no effect of ITI $(F<1)$ and no significant interaction between factors $\left(F_{(1,19)}=2.6, P=0.12\right)$. Sham lesioned mice showed a preference that was significantly above chance at both the $1 \mathrm{~min}$ and $24 \mathrm{~h}$ ITI $\left(1 \mathrm{~min}\right.$ ITI: $t_{(8)}=8.13, P<0.0005$; 24 h ITI: $\left.t_{(8)}=5.13, P=0.001\right)$, whereas hippocampal lesioned mice never showed a significant preference $(t<1$ for both measures). Comparison of the discrimination ratios calculated from the time in arms measure revealed that hippocampal lesioned mice were impaired relative to sham lesioned mice on the $1 \mathrm{~min}$ ITI condition $\left(t_{(19)}=2.14, P=0.045\right)$. Whereas sham lesioned mice showed a preference that was significantly above chance $\left(t_{(8)}=3.01, P=0.017\right)$, hippocampal lesioned mice did not $(t<1)$. Due to the low performance by controls on the long $(24$ h) ITI test, it was not possible to assess whether hippocampal lesions impair long-term spatial memory using the time in arms measure. Both groups failed to show a significant novelty preference ( $t<1$ for both comparisons). However, it is clear that hippocampal lesions, in marked contrast to GluA1 gene deletion (see Experiment 1A; Fig. 2), did not facilitate long-term spatial memory.

During the 2-min novelty preference test hippocampal lesioned mice spent less total time exploring the arms than sham lesioned mice (Sham: $85.96 \mathrm{sec} \pm 2.73 \mathrm{SEM}$; Hpc: $71.72 \mathrm{sec} \pm$ $2.36 \mathrm{SEM})\left(F_{(1,19)}=15.59, P=0.001\right)$. Also, the groups spent a greater total time exploring the arms in the $1 \mathrm{~min}$ ITI condition (82.63 sec $\pm 1.87 \mathrm{SEM})$ than in the $24 \mathrm{~h}$ ITI condition $(75.06 \mathrm{sec} \pm$ $2.55 \mathrm{SEM})\left(F_{(1,19)}=8.15, P=0.01\right)$. There were no other significant effects or interactions $(P>0.1)$. Analysis of the number of arm entries during the test trial showed that both groups made a similar amount of entries $(F<1)$. Mice made more arm entries in the $24 \mathrm{~h}$ ITI condition $(8.92 \pm 0.7 \mathrm{SEM})$ than in the $1 \mathrm{~min}$ ITI condition $(7.44 \pm 0.59 \mathrm{SEM})\left(F_{(1,19)}=9.23, P=0.007\right)$. Importantly, additional analyses of the preference for the Novel arm using a difference score (Novel - Other) yielded a similar impairment in hippocampal lesioned mice (see Supplemental material). 

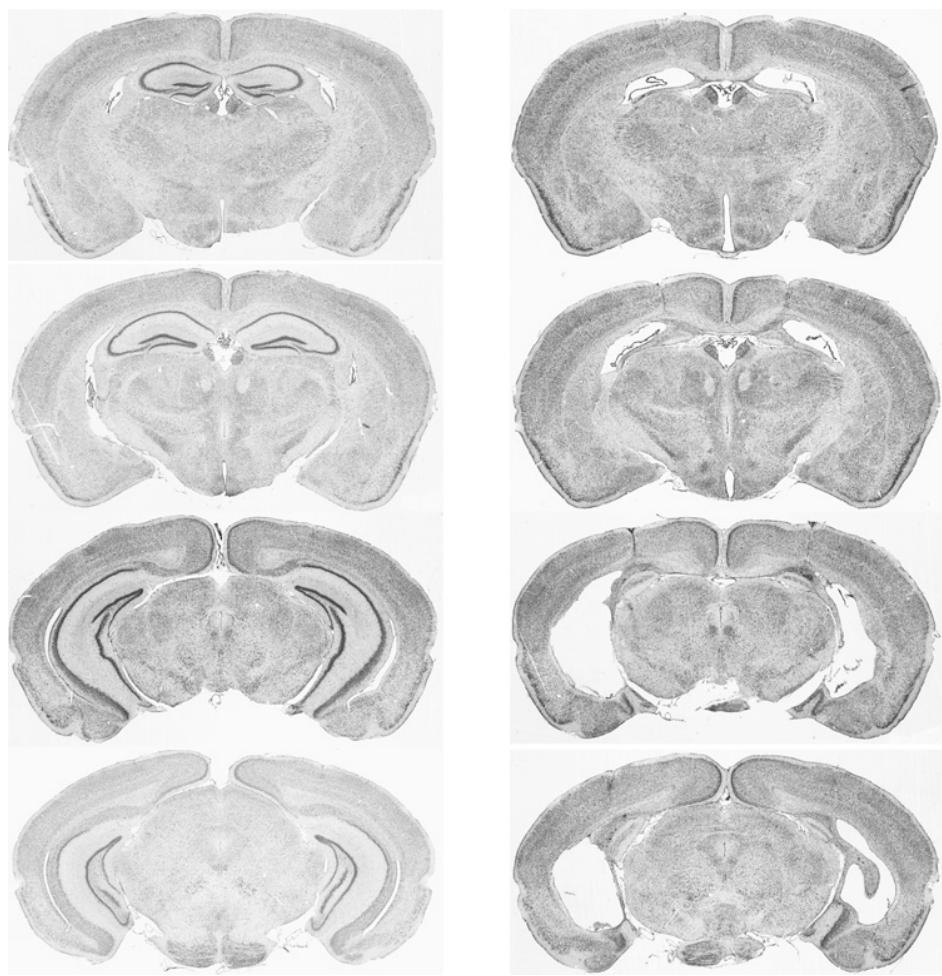

Figure 3. Photomicrographs of four coronal sections from a control brain (left) and a representative hippocampal lesioned brain (right) in C57BL/6JOla mice. The sections are each $\sim 0.7 \mathrm{~mm}$ apart, corresponding to points (from top to bottom) $-1.58,-2.30,-3.08$, and $-3.80 \mathrm{~mm}$ from bregma.

\section{Experiment 2}

In Experiment $1 \mathrm{~A} \mathrm{GluA} 1^{-/-}$mice were found to be impaired when a short (1 min) ITI was used, and enhanced when a $24 \mathrm{~h}$ ITI was used. This interaction between the effects of GluA1 deletion and ITI could be due to GluA1 being important for the extent of learning across trials that are either massed ( 1 min ITI) or spaced ( $24 \mathrm{~h}$ ITI) over time. Alternatively GluA1 may be important for expression of memory across short (1 min) or long ( $24 \mathrm{~h}$ ) intervals. To test these two hypotheses, the intervals between exposure training trials and the interval prior to the novelty preference test were manipulated in a between-subjects factorial design (see Fig. 1). Mice received exposure training with the training trials separated by either a $1 \mathrm{~min}$ or a $24 \mathrm{~h}$ ITI. The number of arm entries during the exposure training trials was recorded. Habituation of activity (i.e., a decrease in the number of arm entries) over exposure training trials was differentially affected by genotype, dependent on the ITI (see Supplemental material). After exposure training, half the mice from each ITI condition then received the novelty preference test after $1 \mathrm{~min}$, and the remaining mice received the test after $24 \mathrm{~h}$.

In agreement with Experiment 1, analysis of the discrimination ratios showed that when the training ITI was long $(24 \mathrm{~h})$ GluA1 ${ }^{-/-}$mice showed a stronger novelty preference than controls (Fig. 4A,B). However, when the training ITI was short (1 min) knockout mice showed a weaker preference than controls. This was confirmed by a significant genotype by training ITI interactions for both performance measures (time in arms: $F_{(1,208)}=6.68$, $P=0.01$; number of arm entries: $F_{(1,208)}=12.41, P=0.001$ ) (Fig. $4 \mathrm{C}, \mathrm{D})$. Simple main effects analysis showed that $\mathrm{GluA} 1^{-1-}$ mice exhibited significantly enhanced spatial memory compared to controls when the training ITI was long $(24 \mathrm{~h})$ (time in arms: $F_{(1,208)}=3.95, P=0.048$; number of arm entries: $F_{(1,208)}=5.56, P=$
0.019). However, the GluA1 ${ }^{-/-}$mice were significantly impaired when the training interval was short (1 min) (number of arm entries: $\left.F_{(1,208)}=6.88, P=0.009\right)$. A similar trend for GluA1 ${ }^{-1-}$ mice to show a weaker novelty preference than the controls in the $1 \mathrm{~min}$ training ITI was found with the time in arms measure, but this effect just failed to reach significance $\left(F_{(1,208)}=2.78, P=0.097\right)$. However, to test whether the results of Experiment 2 replicated the results of Experiment 1A, a planned comparison of the novelty preference scores in the $1 \mathrm{~min}-1 \mathrm{~min}$ ITI condition (which is identical to the 1 min ITI condition, Experiment 1A) was performed. As in Experiment 1A, GluA1 $^{-1-}$ mice were impaired when the interval between the training trials and prior to the novelty preference test was short $\left(F_{(1,49)}=5.07, P=0.029\right)$. Furthermore, whereas wild-type mice showed a greater novelty preference when the training ITI was $1 \mathrm{~min}$, rather than $24 \mathrm{~h}$ (time in arms: $F_{(1,208)}=5.63, P=0.02$; number of arm entries revealed a nonsignificant trend, $\left.F_{(1,208)}=2.18, P=0.1\right)$, knockout mice showed a greater novelty preference in the $24 \mathrm{~h}$ training ITI condition than in the $1 \mathrm{~min}$ ITI condition (number of arm entries: $F_{(1,208)}=12.57, P$ $<0.0005$; time in arms did not reach significance, $\left.F_{(1,208)}=1.6, P=0.2\right)$. One sample $t$-tests showed that wild type and knockout showed a preference for the Novel arm that was significantly above chance for both the short $(1 \mathrm{~min})$ and long $(24 \mathrm{~h})$ ITI $(P<0.02$ for all comparisons), except for the performance of wild-type mice on the $24 \mathrm{~h}$ ITI training conditions using the time in arms measure $\left(t_{(54)}<1, P=0.6\right)$.

The interaction between genotype and testing ITI was not significant (time in arms: $F_{(1,208)}=2.06, P=0.15$; number of arm entries: $F<1$ ). There were no other significant main effects or interactions (all effects $P \geq 0.1$ ). Additional analyses of the preference for the Novel arm using a difference score (Novel - Other) yielded a similar genotype by training ITI interaction (see Supplemental material), but no significant genotype by testing ITI interaction.

During the 2-min novelty preference test, wild-type mice spent a greater total time exploring the Novel and Other arms than knockout mice (WT: $82.63 \mathrm{sec} \pm 2.31 \mathrm{SEM}$; KO: $70.08 \mathrm{sec} \pm$ 2.22SEM) $\left(F_{(1,208)}=15.35, P<0.0005\right)$. Also, mice spent a longer total amount of time exploring the Novel and Other arms when tested after a $1 \mathrm{~min}$ interval than when tested after a $24 \mathrm{~h}$ interval ( 1 min test ITI: $80.4 \mathrm{sec} \pm 2.31 \mathrm{SEM} ; 24 \mathrm{~h}$ test ITI: $72.31 \mathrm{sec} \pm$ 2.22SEM) $\left(F_{(1,208)}=6.39, P=0.012\right)$. There were no other main effects and neither genotype nor test ITI interacted with the other factors (all effects $P \geq 0.3$ ). Knockout mice made a greater total number of arm entries than wild-type mice $\left(F_{(1,208)}=128.5, P<\right.$ $0.0005)$, and this effect interacted with the training interval $\left(F_{(1,208)}=15.0, P<0.0005\right)$. Simple main effects analysis revealed that while knockout mice made more arm entries that the WT mice in both the $1 \mathrm{~min}$ and $24 \mathrm{~h}$ training ITI conditions ( $1 \mathrm{~min}$ ITI: WT: $5.18 \pm 4.9$ SEM; KO: $12.5 \pm 4.8$ SEM; 24 h ITI: WT: $4.56 \pm$ 4.9SEM; KO: $8.16 \pm 4.7 \mathrm{SEM})\left(1 \mathrm{~min}\right.$ ITI: $F_{(1,208)}=115.08, P<$ $0.0005 ; 24$ h ITI: $\left.F_{(1,208)}=27.99, P<0.0005\right)$, they made more arm entries in the 1 min training ITI condition than in the $24 \mathrm{~h}$ 


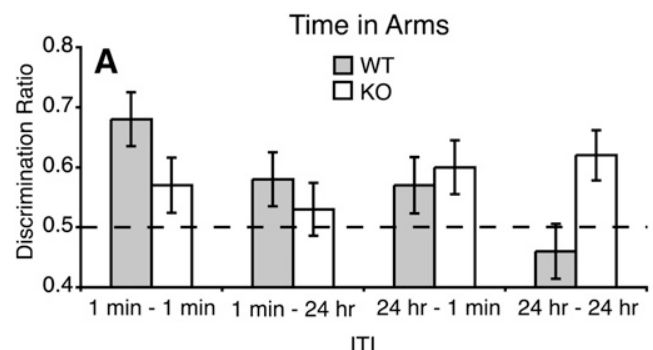

ITI

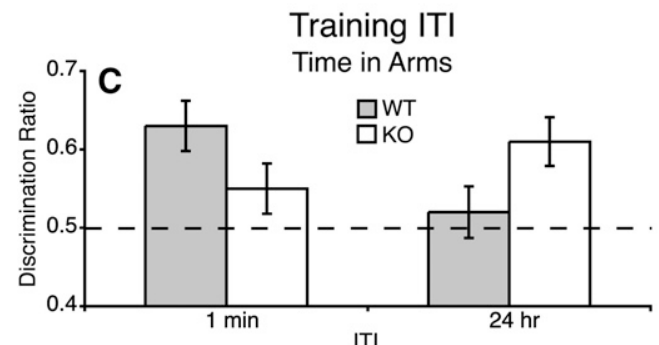

ITI

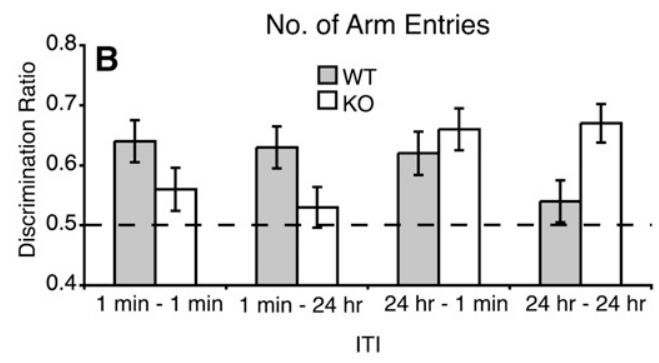

Training ITI

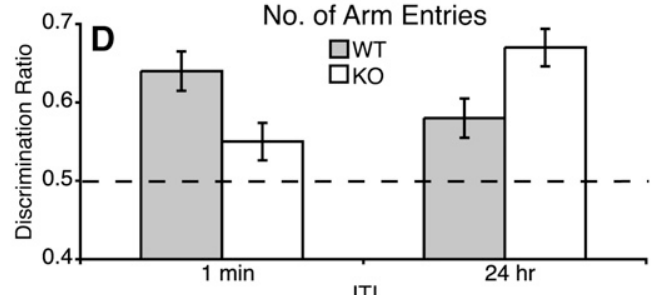

ITI

Figure 4. Experiment 2. GluA1 gene deletion affects learning not expression of spatial memory (wild-type mice [WT]: female, $N=44 ;$ male, $N=66$; knockout mice [KO]: $N=58$; male; $N=56)$. $(A, B)$ Results from each of the four ITI conditions (1 min-1 min; $1 \mathrm{~min}-24 \mathrm{~h} ; 24 \mathrm{~h}-1 \mathrm{~min} ; 24 \mathrm{~h}-24 \mathrm{~h})$ for the time in arms and number of arm entries measures, respectively. (C,D) Results for the 1 min and $24 \mathrm{~h}$ training ITI conditions, but now collapsed across the testing ITI conditions. Results from the time in arms measure $(C)$ and the number of arm entries measure $(D)$. (C,D) GluA1 gene deletion impaired memory when trained with a 1 min ITI, but enhanced memory when trained with a $24 \mathrm{~h} \mathrm{ITI.} \mathrm{Error} \mathrm{bars,} \pm$ SEM.

training ITI condition $\left(F_{(1,208)}=42.24, P<0.0005\right)$, whereas wildtype mice did not $(F<1)$.

\section{Discussion}

GluA1 deletion impaired short-term, but enhanced long-term spatial memory. This pattern of dissociations was found with two separate measures of exploratory behavior (i.e., time in arms, number of arm entries). Experiment 1 showed that when the interval between each exposure trial and before the test trial was short $(1 \mathrm{~min}), \mathrm{GluA}^{-/-}$mice were impaired in comparison to wild-type mice, in terms of spatial novelty preference. However, when the interval was long $(24 \mathrm{~h}) \mathrm{GluA}^{-1-}$ mice displayed memory that was superior to that of the wild types. Importantly, hippocampal lesions disrupted both short-term and long-term spatial memory. Therefore, the enhanced long-term learning in GluA1 ${ }^{-1-}$ mice reflects superior hippocampus-dependent spatial memory. Experiment 2 replicated these findings of impaired shortterm and enhanced long-term memory in GluA1 $1^{-1-}$ mice and, additionally, showed that the effects were dependent on the interval between trials during training and not due to the interval immediately prior to the novelty preference test. The results, therefore, reflect enhanced learning and not simply enhanced performance or expression of memory.

Several accounts of the short-term spatial memory deficit in GluA $1^{-1-}$ mice can be ruled out. First, these mice are not only able to discriminate between different spatial locations (see also Zamanillo et al. 1999; Reisel et al. 2002; Schmitt et al. 2003), but they can do so on the basis of novelty preference. Second, any nonspecific effects of GluA1 deletion on locomotor activity or motivational states cannot explain these time-dependent effects on learning. Any possible confound could not cause the diametrically opposite effect on short-term and long-term learning within the same measure. This is reaffirmed by the fact that two different measures of performance (time in arms and number of arm entries) both demonstrated the same pattern of results. Third, the facilitation observed with long interval training argues against a simple partial degradation of hippocampal function in GluA1 $1^{-/-}$ mice. It is possible that the pattern of impaired short-term spatial memory, but spared long-term spatial memory observed in these animals could reflect a nonspecific, but incomplete, disruption of hippocampal function, with spatial working memory performance simply being more sensitive than reference memory. The facilitation of long-term spatial memory argues strongly against this possibility, but rather is consistent with a dual-process memory model (Wagner 1981). Fourth, these results do not fit with a simple trace decay interpretation of memory. They argue against a model whereby short-term memories are serially converted into long-term memories. Instead, these data argue for two dissociable memory processes.

Indeed, the fact that GluA1 deletion was able to both impair short-term spatial memory and enhance long-term memory, suggests that these forms of memory depend on separate psychological processes that can, under some circumstances, compete with one another. Wagner $(1976,1981)$ suggested that there are independent short-term and long-term processes in memory that can both result in habituation. Consistent with this theory, Davis (1970) showed that whereas short intervals between stimulus exposures produce greater habituation than long intervals, a series of habituation trials separated by long intertrial intervals produces a more durable form of habituation than when a short intertrial interval is used. Thus, habituation can be either short term (e.g., rapid, within-session changes), or long term (e.g., changes that accrue across repeated exposures and influence performance over long intervals). Therefore, short-term habituation is dependent on the recency of the stimulus exposure and, furthermore, this shortterm effect can reduce the opportunity for long-term learning over the course of training. Wagner $(1976,1981)$ suggested that short-term habituation reflects self-generated priming of the memory of a recently presented stimulus, and is nonassociative in nature. The strength of the memory is dependent on the recency of the stimulus exposure and this nonassociative process has only a short-term effect. In contrast, long-term habituation is thought to reflect associative, retrieval-generated priming of the 
memory for a stimulus. It is based on associations formed between stimuli, and therefore the strength of the memory is dependent on the strength of the associations between the stimuli.

A feature of associative learning is that increments in longterm learning are greater when the occurrence of the stimuli is surprising (Rescorla and Wagner 1972; Wagner 1981). Therefore, a short-term memory of a stimulus can retard subsequent associative learning by rendering the occurrence of the stimulus unsurprising, and thus reducing the level of attention that is subsequently paid to that stimulus (Wagner 1981). For example, Sunsay et al. (2004) have shown that the recent presentation of a stimulus (CS1) impairs the ability of that stimulus to enter into associations with other stimuli when subsequently presented. This deficit in conditioning was not seen if a different stimulus (CS2) preceded the CS1-US pairing. Therefore, the impaired conditioning was due to a stimulus-specific short-term memory disrupting long-term, associative learning.

The design of Experiment 2 is similar to that used by Davis (1970). However, whereas Davis found that massed training reduced the long-term habituation of the startle response in rats, here it was found that massed exposure training (i.e., $1 \mathrm{~min}$ training ITI) did not reduce the novelty preference, relative to the effect of spaced training (i.e., $24 \mathrm{~h}$ training ITI) in control mice. In contrast, there was evidence that $\mathrm{GluA} 1^{-1-}$ mice did show, on average, a greater long-term novelty preference with spaced training (i.e., $24 \mathrm{~h}$ training ITI) than with massed training. It is possible that the failure to replicate the effects shown by Davis (1970) is due to the training conditions in Experiment 2 not being optimal for demonstrating enhanced learning following spaced training in control mice. Thus, control mice may not have received enough training to demonstrate the beneficial effects of spaced training. We have conducted further experiments that demonstrate this to be the case: whereas there is no benefit of spaced training with five exposure training trials, spaced training facilitates learning when mice received 10 exposure trials (DJ Sanderson and DM Bannerman, in prep.). This is consistent with Wagner's (1981) theory that long-term learning relies on an incremental strengthening of associative memory.

The fact the GluA1 deletion enhanced long-term memory, while impairing short-term memory, suggests that short-term memory processes may have reduced the extent of long-term learning in control mice. This is consistent with the theoretical view proposed by Wagner (1981) that short-term and long-term memory may compete with one another. It is possible that there may be not only between-trial consequences of short-term memory, but also within-trial effects. Whereas GluA1 knockout mice were impaired when a short ITI was used, because they failed to show between-trial accumulation of short-term memory, they may have been facilitated when a long interval was used because within-trial accumulation of short-term memory reduced the extent of long-term learning in wild-type mice. This is similar to the reduction in conditioning seen when a long CS duration is used compared to a shorter CS duration (Smith 1968). Therefore, GluA1 deletion may facilitate long-term learning by reducing the negative within-trial effects of short-term memory. Simulations of Wagner's SOP model demonstrate that a reduction in the decay rate of memories from active processing (A1) to a refractory state (A2) can cause greater long-term memory, while reducing shortterm memory (see Supplemental material).

Previous studies with GluA1 ${ }^{-1-}$ mice have fractionated hippocampus-dependent, spatial memory into two distinct components based on spatial working memory and spatial reference memory performance (Reisel et al. 2002; Schmitt et al. 2003). The present data suggest a psychological account for this dissociation in which the impaired spatial working memory performance of $\mathrm{GluA}^{-/-}$mice likely reflects a role for GluA1 in the short-term habituation to recently visited spatial locations. The preference that normal animals show for the Novel arm during the spontaneous exploration Y-maze task, in the present study reflects their habituation to the two pre-exposed arms during the recent training trials. Similarly, during win-shift behaviors on appetitive maze tasks, control animals choose unvisited arms over recently visited arms. GluA1 ${ }^{-1-}$ mice are unable to select between arms on the basis of the relative recency in which the arms were experienced. In contrast, spatial reference memory performance reflects the ability to form associations between spatial locations and outcomes (e.g., an escape platform or a food reward) and is GluA1 independent.

In contrast to GluA1 ${ }^{-1-}$ mice, both short-term and long-term spatial memory was impaired by hippocampal lesions (Experiment 1B). Therefore, the enhanced long-term spatial memory in $\mathrm{GluA}^{-/-}$mice reflects facilitated hippocampus-dependent learning and not an increase in hippocampus-independent learning processes. The results with hippocampal lesioned mice are consistent with the idea that the hippocampus is required for both selfgenerated priming and associative, retrieval-generated priming of spatial memories, possibly reflecting a fundamental role in spatial information processing (O'Keefe and Nadel 1978). However, they are also consistent with the possibility of a more general role for the hippocampus in both self-generated (Marshall et al. 2004), and retrieval generated priming of the memory of a stimulus, irrespective of whether that stimulus is spatial or nonspatial (Honey et al. 1998; Honey and Good 2000).

To conclude, GluA1 deletion disrupts a rapidly induced, short-lasting form of hippocampal synaptic plasticity (Hoffman et al. 2002; Romberg et al. 2009) and, in parallel, prevents a form of hippocampus-dependent, short-term spatial memory. This, in turn, reveals the presence of other synaptic processes that independently support the formation of long-term memories. Thus, GluA1 deletion can, under certain conditions, enhance spatial learning by reducing the detrimental effects of short-term memory processes on subsequent learning. Importantly, the present results demonstrate superior long-term, spatial memory in animals deficient in a form of hippocampal synaptic plasticity (Zamanillo et al. 1999; Hoffman et al. 2002; Romberg et al. 2009). These data thus provide novel support for Wagner's dual-process model of memory within the spatial domain.

\section{Materials and Methods}

\section{Subjects}

Experimentally naïve, age-matched, male and female, wild-type, and GluA $1^{-l-}$ mice, bred in the Department of Experimental Psychology, University of Oxford, served as subjects in these experiments. Mice were from a background of the 129S2sv strain crossed with the C57BL/6J/Ola strain (see Zamanillo et al. [1999] for details of genetic construction, breeding, and subsequent genotyping). Mice were $\sim 16 \mathrm{wk}$ old at the start of behavioral testing. Experiment 1 also used two groups of female C57BL/6J/ Ola mice obtained from Harlan OLAC Ltd., that received either bilateral $\mathrm{N}$-methyl-D-aspartate (NMDA)-induced cytotoxic hippocampal lesions (HPC: $N=12$ ) or sham surgery (Sham: $N=9$ ). Hippocampal or sham lesions were performed when animals were $\sim 12-13$ wk old. Surgical procedures and stereotaxic coordinates were as reported by Deacon et al. (2002). Sham lesioned mice received craniotomies, but no further procedures. Mice received a minimum of 2 wk recovery after surgery before behavioral testing. At the end of behavioral testing sham and hippocampal lesioned mice were anaesthetized and perfused transcardially with physiological saline followed by $10 \%$ formol saline. Their brains were removed and stored in formol saline. They were subsequently placed in 30\% sucrose-formalin solution for $24 \mathrm{~h}$, frozen, sectioned coronally, and stained with cresyl violet. 
All mice were caged in groups of litter mates (2-6 per cage). Mice were housed in a temperature controlled room that was illuminated between 7:00 a.m. and 7:00 p.m. Mice had ad libitum access to food and water. Mice were tested during the light cycle. All experiments were conducted under the auspices of the UK Home Office Project and personal licenses held by the authors.

\section{Apparatus}

A Y-maze constructed from transparent Perspex was mounted on an opaque square Perspex board $(64.5 \mathrm{~cm} \times 56.5 \mathrm{~cm})$. The walls of the Y-maze were $20 \mathrm{~cm}$ high and $0.5 \mathrm{~cm}$ thick. Each arm was $30 \mathrm{~cm}$ long and $8 \mathrm{~cm}$ wide. The maze was placed in a room containing a variety of extramaze cues. During exposure training trials the entrance to one arm (the Novel arm) was blocked using a sheet of opaque Perspex. In total, six rooms were used (Experiment 1A: rooms A and B; Experiment 1B: rooms A-F; Experiment 2: room C). These rooms contained extramaze cues that made them distinct from each other.

\section{Procedure}

In both Experiments 1 and 2 mice received repeated exposures to two arms of a Y-maze (Start and Other arms; see Fig. 1A). At the end of exposure training mice received a novelty preference test in which they were now allowed to explore all three arms (i.e., the previously exposed Start and Other arms, and the previously unexplored Novel arm). The arm of the Y-maze located closest to the experimenter was always used as the Start arm. Mice were allocated one of the remaining arms as the pre-exposed Other arm, and this was fully counterbalanced with respect to group.

Mice received five 2-min exposure trials. At the start of a trial the mouse was placed at the end of the Start arm and allowed to explore the Start arm and the Other arm. Access to the Novel arm was blocked during the exposure trials. At the end of each trial the mouse was removed from the maze and returned to its home cage. If the interval between the trials was $24 \mathrm{~h}$ then the home cage was returned to the holding room overnight before the subsequent trial. Activity across the five exposure trials was measured by recording the number entries into the Other and Start arms, after mice had left the Start arm. The analyses of these results are shown in the Supplemental material.

After the completion of exposure training mice received a novelty preference test. At the start of the novelty preference test the mouse was placed at the end of the Start arm and now allowed to explore the Start, Other, and Novel arms. Once the mouse had left the Start arm, by placing all four paws outside of the arm, exploratory behavior was assessed for $2 \mathrm{~min}$. This assured that the preference for the Novel arm was not influenced by the time taken to leave the Start arm by each mouse. During the test the time spent in each arm and the number of entries into each arm were recorded. An arm entry was defined as when a mouse had placed all four paws into an arm. A mouse was considered to have left an arm once all four paws were placed outside of the arm.

Preference for the Novel arm was calculated as a discrimination ratio (Novel/[Novel + Other]) for both the time in arms and number of arm entries. Scores greater than 0.5 indicate a preference for the Novel arm. The novelty preference was also calculated as a difference score (see Supplemental material).

\section{Experiment 1}

In Experiment 1A, wild-type (female: $N=12$; male: $N=8$ ) and GluA1 ${ }^{-/-}$mice (female: $N=8$; male: $N=6$ ) were tested under two conditions in a within-subjects design. In the first condition the interval between each of the exposure trials and before the novelty preference test was $1 \mathrm{~min}$ ( $1 \mathrm{~min}$ ITI; see Fig. 1B). In the second condition the interval was $24 \mathrm{~h}$ (24 h ITI). Testing of each condition occurred in different rooms that contained distinct extramaze cues (rooms A and B). The order of testing of the two conditions and the order of testing in the two rooms was fully counterbalanced. Within each of the counterbalanced groups the location of the Novel and Other arms were also counterbalanced.

Experiment 1B comprised a group of sham $(N=9)$ and hippocampal lesioned mice $(N=12)$ that were tested the same as in Experiment 1A (see Fig. 1B). All procedures were the same. However, to test the reliability of the results the task was repeated three times. Therefore, mice were trained and tested for a spatial novelty preference in the $1 \mathrm{~min}$ and $24 \mathrm{~h}$ ITI conditions on three occasions each. Testing took place in three pairs of rooms (A and B; $\mathrm{C}$ and $\mathrm{D} ; \mathrm{E}$ and $\mathrm{F})$. The order of testing in the pairs of rooms was counterbalanced in the same manner as for rooms A and B (as described previously). The order of testing for short (S), $1 \mathrm{~min}$, intervals and long (L), $24 \mathrm{~h}$, intervals across the three pairs of test was SLLSSL for approximately half of the mice. For the remaining mice the order was LSSLLS. The preference for the Novel arm over the familiar arm was calculated using the scores for the time in arms measure and the number of arm entries measure, averaged across replications.

\section{Experiment 2}

In Experiment 2 experimentally naïve wild-type (female: $N=44$; male: $N=66$ ) and GluA1 ${ }^{-1-}$ mice (female: $N=58$; male: $N=56$ ) were tested in one of four conditions in a 2 (training ITI: 1 min vs. $24 \mathrm{~h}) \times 2$ (testing ITI: 1 min vs. $24 \mathrm{~h}$ ) between-subjects design. One group of mice received exposure training with an interval of $1 \mathrm{~min}$ between the trials ( 1 min training ITI). For the other group the interval was $24 \mathrm{~h}$ ( $24 \mathrm{~h}$ training ITI). Approximately half of the mice within each group then received the novelty preference test 1 min after the last exposure trial ( 1 min test ITI). The remaining mice received the novelty preference test $24 \mathrm{~h}$ after the last exposure trial ( $24 \mathrm{~h}$ test ITI; see Fig. 1C). Within each condition the locations of the Other and Novel arms were counterbalanced.

\section{Analyses}

The preference for the Novel arm was calculated as a discrimination ratio (Novel/Novel + Other) for both the time in arms and number of arm entries measures. Experiment $1 \mathrm{~A}$ was analyzed using a 2 (Genotype: WT, KO) $\times 2$ (ITI: $1 \mathrm{~min}, 24 \mathrm{~h}) \times 2$ (Sex: male, female) multifactorial ANOVA, in which ITI was a within-subject factor. A preliminary analysis included the order of testing of the different ITI conditions as a factor. It was found that testing order had no significant effect in either the time in arms analysis or the number of arm entries measures, and did not significantly interact with other factors. Therefore, this factor was removed from the final analyses. Experiment $1 \mathrm{~B}$ was analyzed using a 2 (Lesion: Sham, Hpc) $\times 2$ (ITI: $1 \mathrm{~min}, 24 \mathrm{~h}$ ) ANOVA, in which ITI was a within-subject factor. A preliminary analysis also included the factors of testing order and the three tests as a repeated measure. Testing order had no significant effect and did not significantly interact with other factors and, therefore was removed from the final analyses. Similarly, the test had no significant effect demonstrating that performance was stable across the repeated test conditions. Experiment 2 was analyzed using a 2 (genotype: WT, KO) $\times 2$ (training interval: $1 \mathrm{~min}, 24 \mathrm{~h}) \times 2$ (testing interval: 1 min, $24 \mathrm{~h}) \times 2$ (sex: male, female) ANOVA, in which all factors were between-subjects manipulations. All significant interactions were analyzed using simple main effects analysis using the pooled error term derived from the original ANOVA.

Parallel analyses of the preference for the Novel arm using a difference score (Novel - Other), that calculates a preference that is independent of individual differences in exploratory behavior, were also performed (see Supplemental material).

\section{Acknowledgments}

This work was supported by the Wellcome Trust (65298 and 074385). We thank Greg Daubney and Jonathan Flint for assistance with histology and genotyping, respectively.

\section{References}

Barker GR, Warburton EC, Koder T, Dolman NP, More JC, Aggleton JP, Bashir ZI, Auberson YP, Jane DE, Brown MW. 2006. The different effects on recognition memory of perirhinal kainate and NMDA glutamate receptor antagonism: Implications for underlying plasticity mechanisms. J Neurosci 26: 3561-3566. 
Collingridge GL, Olsen RW, Peters J, Spedding M. 2009. A nomenclature for ligand-gated ion channels. Neuropharmacology 56: 2-5.

Davis M. 1970. Effects of interstimulus interval length and variability on startle-response habituation in the rat. J Comp Physiol Psychol 72: 177192.

Deacon RM, Bannerman DM, Kirby BP, Croucher A, Rawlins JN. 2002. Effects of cytotoxic hippocampal lesions in mice on a cognitive test battery. Behav Brain Res 133: 57-68.

Groves PM, Thompson RF. 1970. Habituation: A dual-process theory. Psychol Rev 77: 419-450.

Hoffman DA, Sprengel R, Sakmann B. 2002. Molecular dissection of hippocampal theta-burst pairing potentiation. Proc Natl Acad Sci 99: 7740-7745.

Honey RC, Good M. 2000. Associative modulation of the orienting response: Distinct effects revealed by hippocampal lesions. J Exp Psychol 26: $3-14$.

Honey RC, Watt A, Good M. 1998. Hippocampal lesions disrupt an associative mismatch process. J Neurosci 18: 2226-2230.

Malinow R, Malenka RC. 2002. AMPA receptor trafficking and synaptic plasticity. Annu Rev Neurosci 25: 103-126.

Marshall VJ, McGregor A, Good M, Honey RC. 2004. Hippocampal lesions modulate both associative and nonassociative priming. Behav Neurosci 118: $377-382$.

Martin SJ, Grimwood PD, Morris RG. 2000. Synaptic plasticity and memory: An evaluation of the hypothesis. Annu Rev Neurosci 23: 649-711.

Morris RG, Anderson E, Lynch GS, Baudry M. 1986. Selective impairment of learning and blockade of long-term potentiation by an $N$-methyl-Daspartate receptor antagonist, AP5. Nature 319: 774-776.

O'Keefe J, Nadel L. 1978. The hippocampus as a cognitive map. Oxford University Press, Oxford.

Reisel D, Bannerman DM, Schmitt WB, Deacon RM, Flint J, Borchardt T, Seeburg PH, Rawlins JN. 2002. Spatial memory dissociations in mice lacking GluR1. Nat Neurosci 5: 868-873.

Rescorla RA, Wagner AR. 1972. A theory of Pavlovian conditioning: Variations in the effectiveness of reinforcement and nonreinforcement. In Classical conditioning, II: Current research and theory (eds. AH Black and WF Prokasy), pp. 64-99. Appleton-Century-Crofts, New York.

Romberg C, Raffel J, Martin L, Sprengel R, Seeburg PH, Rawlins JNP, Bannerman DM, Paulsen O. 2009. Induction and expression of GluA1 (GluR-A)-independent LTP in the hippocampus. Eur J Neurosci 29: 1141-1152.
Sanderson DJ, Gray A, Simon A, Taylor AM, Deacon RM, Seeburg PH, Sprengel R, Good MA, Rawlins JN, Bannerman DM. 2007. Deletion of glutamate receptor-A (GluR-A) AMPA receptor subunits impairs onetrial spatial memory. Behav Neurosci 121: 559-569.

Sanderson DJ, Good MA, Seeburg PH, Sprengel R, Rawlins JN, Bannerman DM. 2008. The role of the GluR-A (GluR1) AMPA receptor subunit in learning and memory. Prog Brain Res 169: 159-178.

Schmitt WB, Deacon RM, Seeburg PH, Rawlins JN, Bannerman DM. 2003. A within-subjects, within-task demonstration of intact spatial reference memory and impaired spatial working memory in glutamate receptorA-deficient mice. J Neurosci 23: 3953-3959.

Smith MC. 1968. CS-US interval and US intensity in classical conditioning of the rabbit's nictitating membrane response. J Comp Physiol Psychol 66: 679-687.

Sunsay C, Stetson L, Bouton ME. 2004. Memory priming and trial spacing effects in Pavlovian learning. Learn Behav 32: 220-229.

Wagner AR. 1976. Priming in STM: An information processing mechanism for self-generated or retrieval-generated depression in performance. In Habituation: Perspectives from child development, animal behavior, and neurophysiology (eds. TJ Tighe and RN Leaton), pp. 95-128. Lawrence Erlbaum Associates, Hillsdale, NJ.

Wagner AR. 1978. Expectancies and the priming of STM. In Cognitive processes in animal behavior (eds. SH Hulse et al.), pp. 177-209. Lawrence Erlbaum Associates, Hillsdale, N.J.

Wagner AR. 1979. Habituation and memory. In Mechanisms of learning and motivation: A memorial volume for Jerzy Konorski (eds. A Dickinson and RA Boakes), pp. 53-82. Erlbaum, Hillsdale, NJ.

Wagner AR. 1981. SOP: A model of automatice memory processing in animal behavior. In Information processing in animals: Memory mechanisms (eds. NE Spear and RR Miller), pp. 5-47. Lawrence Erlbaum Associates Inc, Hillsdale, NJ.

Whitlow JW, Wagner AR. 1984. Memory and habituation. In Habituation, sensitization and behavior (eds. HVS Peeke and L Petrinovich), pp. 103153. Academic, New York.

Zamanillo D, Sprengel R, Hvalby O, Jensen V, Burnashev N, Rozov A, Kaiser KM, Koster HJ, Borchardt T, Worley P, et al. 1999. Importance of AMPA receptors for hippocampal synaptic plasticity but not for spatial learning. Science 284: 1805-1811.

Received January 12, 2009; accepted in revised form March 31, 2009. 


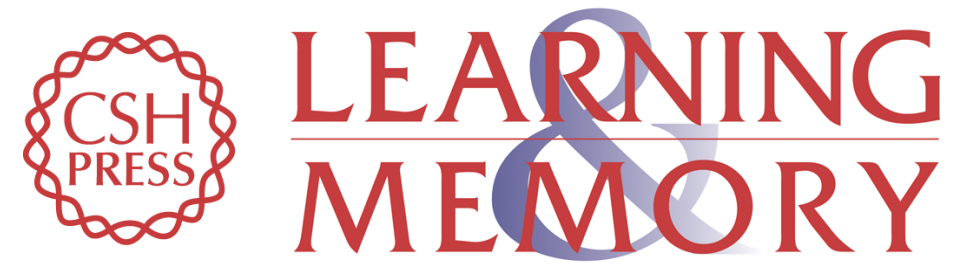

\section{Enhanced long-term and impaired short-term spatial memory in GluA1 AMPA receptor subunit knockout mice: Evidence for a dual-process memory model}

David J. Sanderson, Mark A. Good, Kathryn Skelton, et al.

Learn. Mem. 2009, 16:

Access the most recent version at doi:10.1101//m.1339109

Supplemental Material

References

License Freely available online through the Learning \& Memory open access option.

Email Alerting Receive free email alerts when new articles cite this article - sign up in the box at the Service top right corner of the article or click here. 